\section{TOBACCO AMBLYOPIA.}

BY GUSTAVUS HARTRIDGE. F.R.C.S.,

Ophthalmic Burgeon to St. Bartholomew's Hospital, Chatham; and AssistantSurgeon to the Royal Westminster Ophthalmic Hospital.

TWENTY cases of tobacco amblyopis having come under my care luring the past twelve months at the Royal Westminster Ophthalmic Hospital, I think they may prove a useful addition to Mr. Shears' list of cases, published in the number of the Britisi Medical JourNal for June 21st, 1884. I hare arranged the cases in the convenient tabular form suggested by Mr. Jonathan Hutchinson. The chief points relied on in the diagnosis were $(a)$, Rapid failure of sight with no ophthalmoscopic or other change to account for the great loss of vision ; (b), Central colour scotoma ; (c), Excessive smoking.
Of the twenty cases, all improved considerably, and in thirteon complete recovery may be said to have resulted. In one instance the pationt was a woman (the only one that has ever come under my notice sut. fering from tobacco amblyopia), another was a toetotallor, and four chewed as well as smoked; but in no instance have I mot with a case of amblyopia in a person who used tobacco for chewing ouly.

As regards treatment, the essentisl point was the total discontinuance of smoking, instead of diminishing the quantity and quality of the tobacco, as suggested by some writers. In half the cases strychnine was administered, in the other half a placebo, with apparently equally good results. Galvanism was tried in three cases, but with no appreciable effect. $\Delta$ fter recovery, three or four pipes of mild tobacco daily, wore allowed, but a caution was given that excessive smoking would be likely to produce a return of the amblyopia. In my ex. perience optic atrophy has nevor resulted.

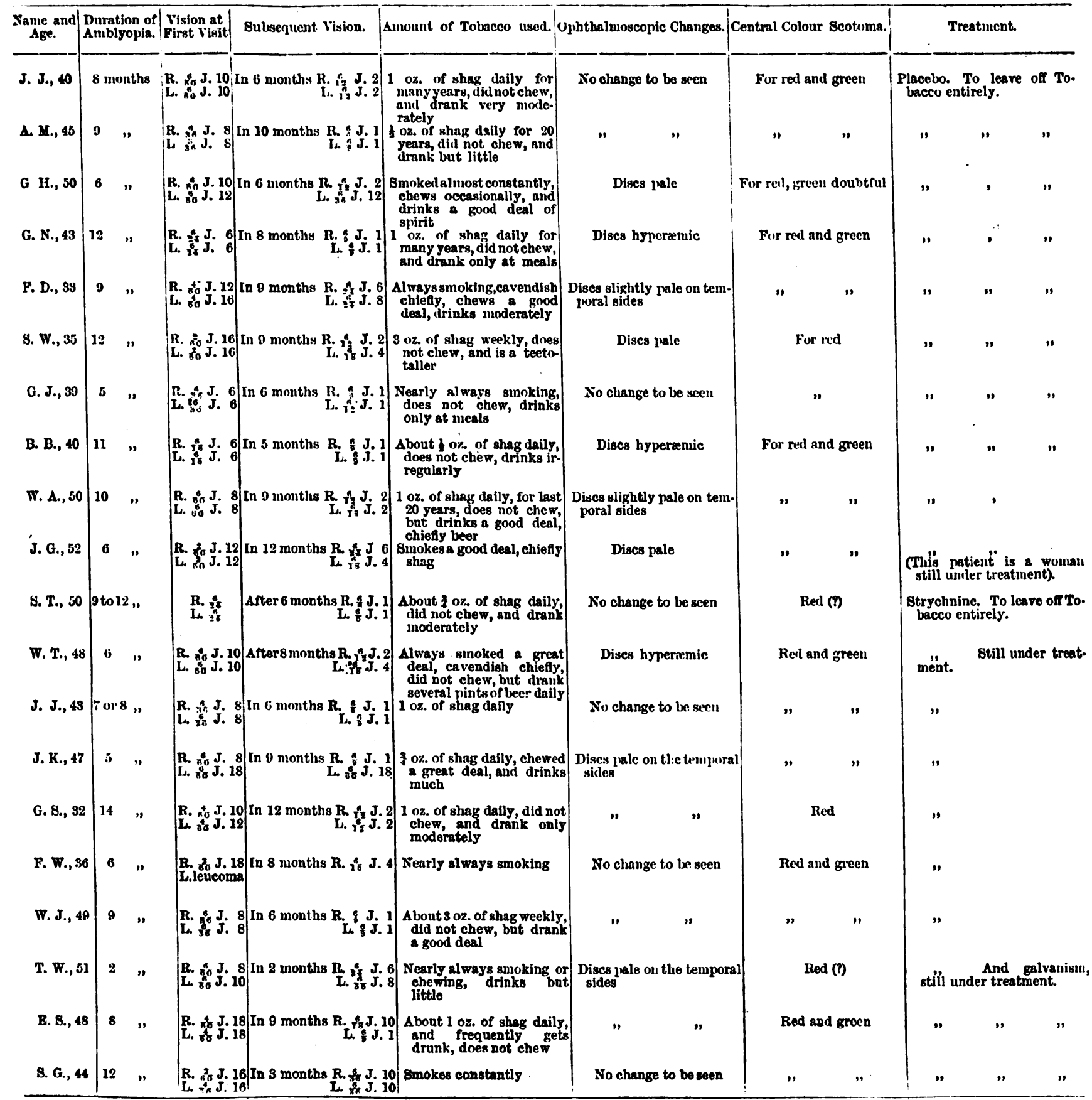

